\title{
The Ups and Downs of Far East Salmon Stocks During Recent Decades: Some Considerations and Possible Causes
}

\author{
Andrey S. Krovnin, Kirill K. Kivva, George P. Moury, and Alexandra A. Sumkina \\ Russian Federal Research Institute of Fisheries and Oceanography, Russian Federation, $17 \mathrm{~V}$. \\ Krasnoselskaya, Moscow, Russia
}

Keywords: East Kamchatka pink salmon, West Kamchatka pink salmon, odd and even-year generations, catch, heat content, ice cover

Over recent decades Far East pink salmon stocks have undergone considerable variations associated with the strengthening of short-term climate variability in the North Pacific. The last minimum of total pink salmon catch (147,500 metric tons) in 2014 was followed by its growth to a maximum of about 511,000 metric tonnes in 2018 . This rise of catches was associated with an increase in heat content of surface waters in the northern North Pacific and Far East Seas in 2014-2019. This presumably created favorable environmental conditions for pink salmon stocks, especially for those spawning in Kamchatka rivers, during their marine period of life. The growth of catches was essentially caused by an unusual increase in catch of even-year generations of East Kamchatka (EK) pink salmon, which were not a dominant stock. From 2012 to 2018, this catch rose more than six times, from 16,730 metric tonnes up to 111,250 metric tonnes, respectively (Fig. 1). In 2018, the share of EK pink salmon in the total Russian pink salmon catch reached almost $22 \%$.

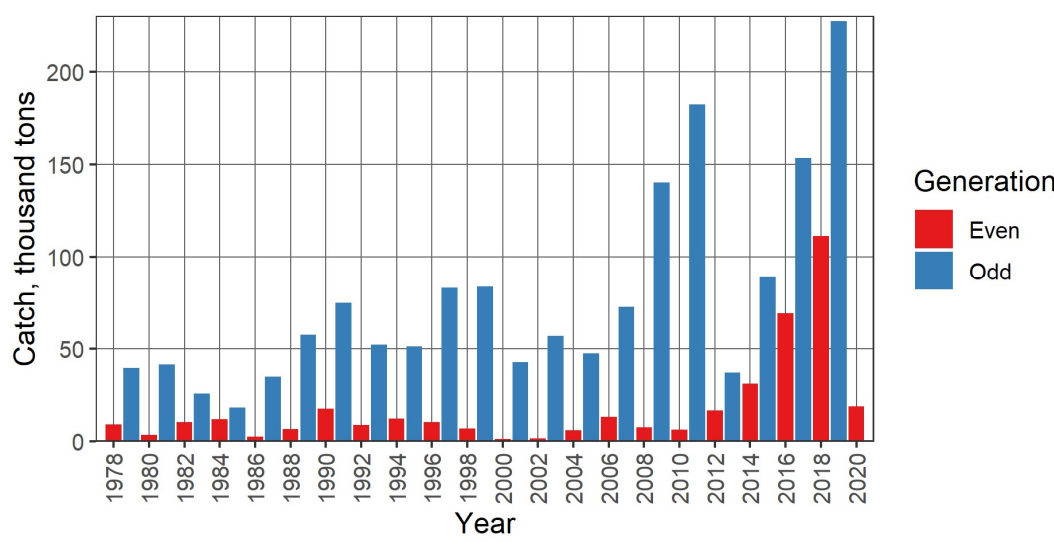

Fig. 1. Catches of East Kamchatka pink salmon, 1978-2020.

In 2020, the situation changed. The total pink salmon catch was only 179,400 metric tonnes, 1.25 times lower than the expected volume of 222,800 metric tonnes. The maximal underfishing relative to the projected volume was noted near the East Kamchatka-20,700 metric tonnes and 82,700 metric tonnes, respectively. Thus, the catch constituted only $1 / 4$ of the expected value.

It may be supposed that a decrease in the total pink salmon catch in 2020 was associated with changes of abiotic conditions in the winter season of 2019-2020. The main purpose of this paper is an attempt to reveal the environmental factors which caused the decrease in pink salmon catches, and especially East Kamchatka pink salmon, in 2020.

The Kamchatka pink salmon catch statistics for 1978-2020 are available online from the NPAFC website (https://npafc.org). Heat content in the 0-100 m layer in the North Pacific region north of $40^{\circ} \mathrm{N}$ was calculated using the EN4 dataset v.4.2.1 with a spatial resolution of $1^{\circ} \times 1^{\circ}$ and temporal resolution of 1 month (Good et al. 2013). The calculations were made for each month from December to April during the 1978-2020 period. We suppose that the areas with the maximal absolute values of correlation coefficients between the catches and heat content coincide with the wintering areas of pink salmon or are located close to them. The length of time series under consideration is $n=21$ years with the number of degrees of freedom $v=19$. For $v=19$, all correlation coefficients with absolute values equal to, or higher than, 0.43 are statistically significant at $p \leq 0.05$. The data on ice concentration for the 1979-2020 period were taken from Climate Data Record (CDR) NOAA/NSIDC (Meier et al. 2017, https://nsidc.org/data/G02135/versions/3).

Figure 1 shows the correlation pattern between the heat content in the upper 0-100 $\mathrm{m}$ water layer and catches of EK pink salmon in even years. In December, the area of maximal (positive) correlation coefficients exceeding 
$0.50-0.60$ is located north and south of the Aleutian Islands, with a center at $170^{\circ} \mathrm{W}$ (Fig. 2a). By February, this area is displaced northward and expands, covering almost the entire southern Bering Sea (Fig. 2b). In April, the area with correlation coefficients above 0.60 narrows (Fig. 2c). This allows for the suggestion that a considerable number of fish could winter in the southern Bering Sea, especially during the second half of the 2010s, when the anomalous warming was observed in the Northeast Pacific and southeastern Bering Sea.

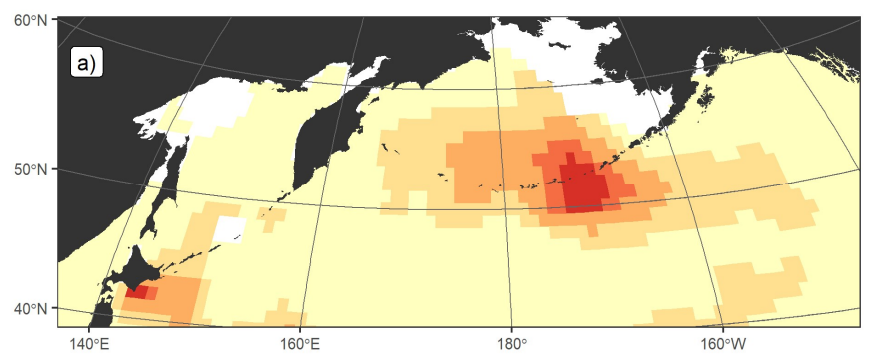

Fig. 2. Correlation patterns between catches of EK pink salmon in even years and heat content in the upper 0 $100 \mathrm{~m}$ water layer for December (a), February (b), and April (c) during 1978-2020.
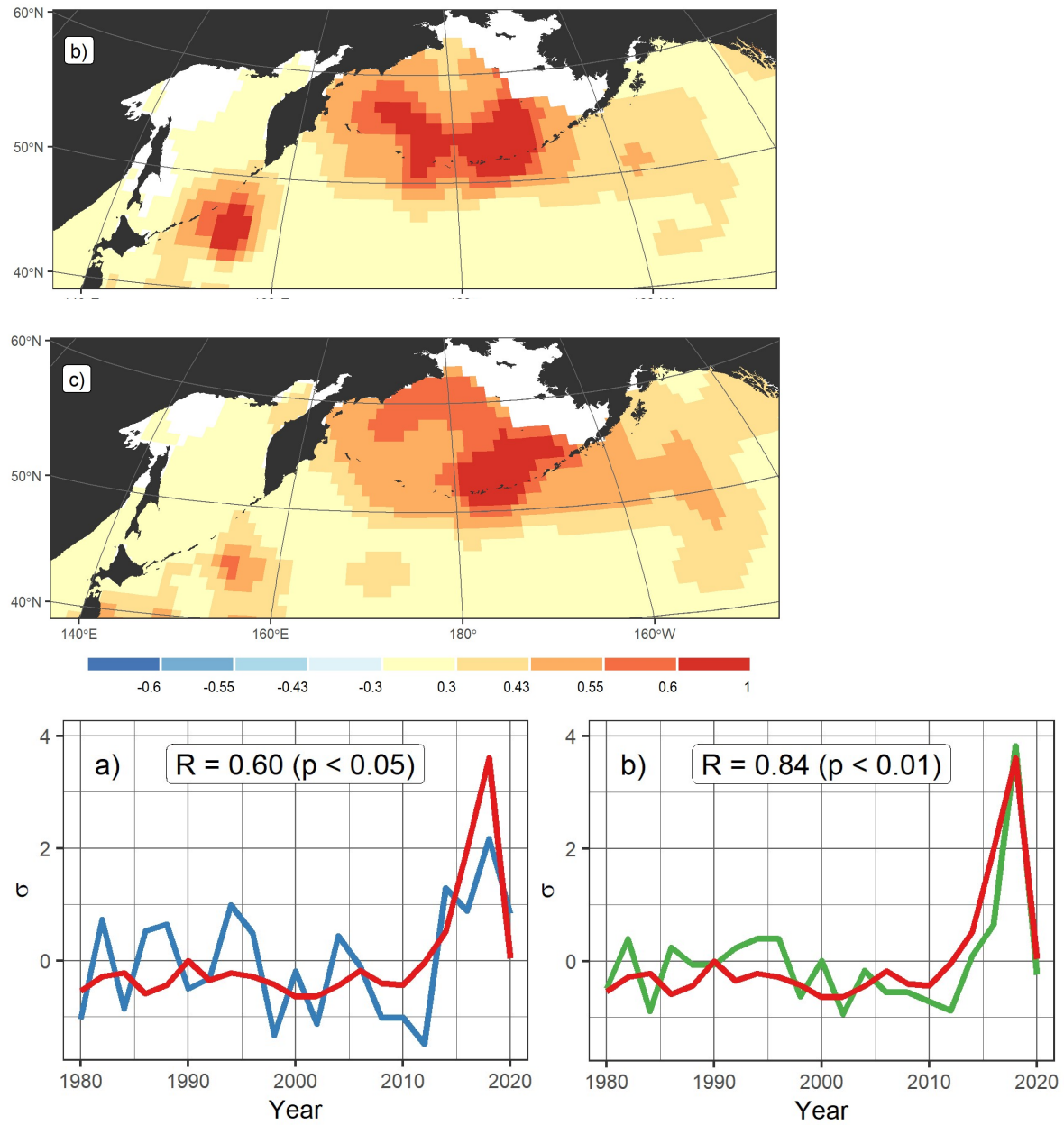

Fig. 3. Normalized anomalies of EK pink salmon catches in even years and latitude of geographical center (centroid) of ice cover in the Bering Sea (a); latitudinal position of the ice edge at $175^{\circ} \mathrm{W}$ in February during the 1980-2020 period.

The suggestion is confirmed by the high statistical relationship between the catches in even years and characteristics of the Bering Sea ice cover in the winter-spring period. As an example, Figure 3a shows changes in the latitude anomalies of the geographical center (centroid) of ice cover in the sea in February and anomalies of the even-year catches of EK pink salmon. Both time series in this Figure were normalized to the corresponding standard deviation. In 1978-2010, the relatively small fluctuations in both characteristics, not exceeding one standard deviation $( \pm \sigma)$, were observed. Beginning from 2012, a northward shift of the geographical center of the ice cover, with a maximum in 2018, was noted. In the same years, there was an increase in the even-year catches of EK pink salmon, also with a maximal volume in 2018. In 2020, the extension of ice cover in the Bering Sea 
returned to the mean long-term situation. At the same time, the catches decreased significantly. The correlation coefficient between the time series under consideration for the entire period from 1978 to 2020 is $0.60(p<0.05)$. The correlation coefficient becomes even higher, if the latitudinal position of the ice edge at $175^{\circ} \mathrm{W}$ is used as a characteristic of the ice cover (Fig. 3b). In this case, its value reaches $0.84(p<0.01)$. The minimum area of ice cover and the extreme northern position of its edge in the Bering Sea were noted in 2018. In the same year, the record catch of EK pink salmon for even-year generations (111,250 metric tonnes) was obtained.

Thus, the growth of the even-year catches of EK pink salmon from 2014-2018 coincided with an anomalous decrease of ice cover area in the Bering Sea and shift of its margin far to the north. It should be noted that the positive relationship between catches and characteristics of ice cover can be interpreted in two ways. First, the extension of ice cover reflects the general thermal state of the sea: the higher heat content in the upper layer results in a lower intensity of ice formation, and vice versa. In this case, the ice cover is only an indicator of the thermal regime of the waters. Second, if the even-year generations of EK pink salmon really winter in the southern Bering Sea, then reduction of the ice cover area with a shift of its southern margin to the north, contributes to the expansion of the winter-feeding area and, therefore, a better survival of the corresponding generation. The opposite situation leads to a lower survival and, as a result, to decrease in catches. Thus, the return of thermal and ice conditions in the Bering Sea and the near-Aleutian region to the mean long-term level in the winter of 2019-2020 obviously contributed to the less favorable survival conditions for the 2018 East Kamchatka pink salmon generation and recovering of the "saw-shaped" variations of biomass observed during the recent decades and, as a result, the similar variations of catches, with their high volumes in odd years and low volumes in even years. It should be noted that the return of thermal and ice conditions in the Bering Sea to the mean long-term level is also confirmed by the results of the analysis given in the paper (Eisner 2020).

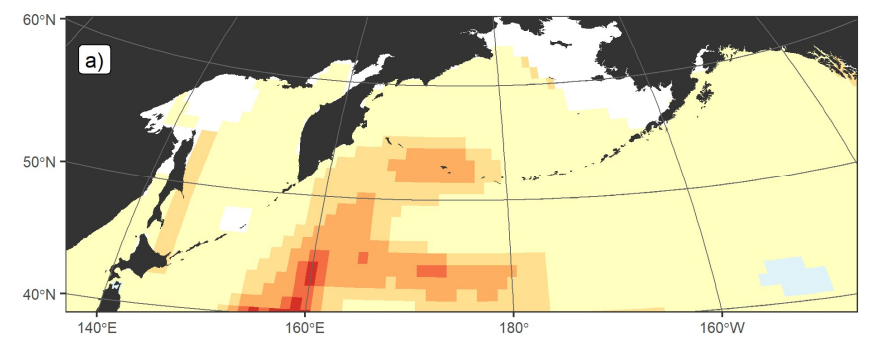

Fig. 4. Correlation patterns between catches of EK pink salmon in odd years and heat content in the upper 0-100 m water layer for December (a), February (b), and April (c) during 1979-2019.
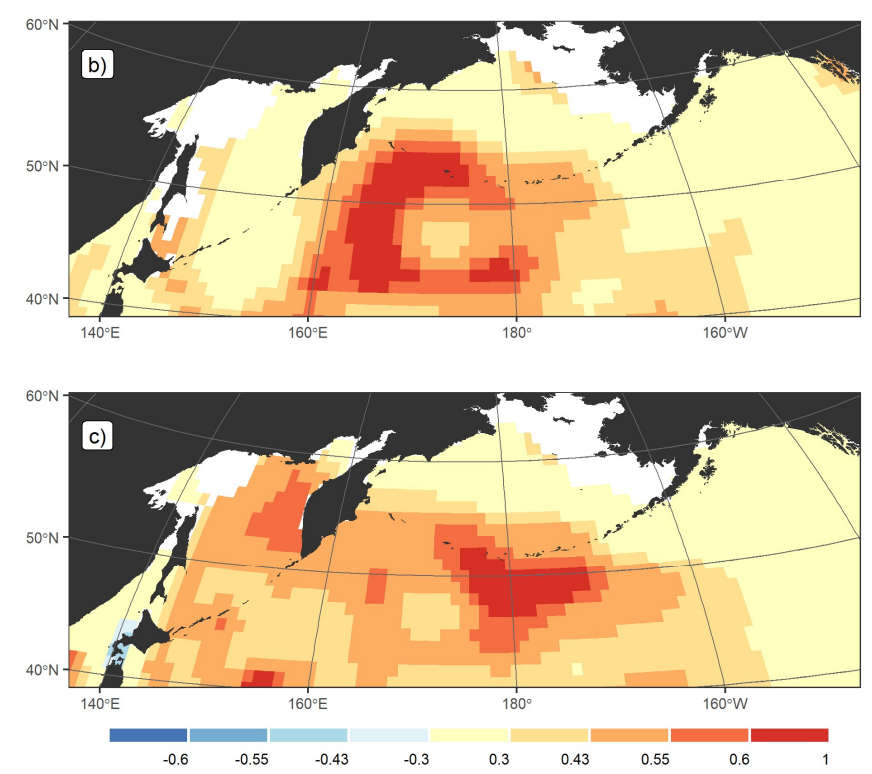

The positive relationship of catches with the winter heat content in the upper 0-100 $\mathrm{m}$ layer is observed for both even- and odd-year generations of EK pink salmon (Fig. 4). However, judging by the position of the domain with maximal correlations, the odd-year generations of EK pink salmon winter further west than the even-year generations, in the area of the western Subarctic Gyre between $160-170^{\circ}$ E (Fig. 4a, b), and in the late winter they probably migrate eastward to the area of $180-170^{\circ} \mathrm{W}$ (Fig. $4 \mathrm{c}$ ). 

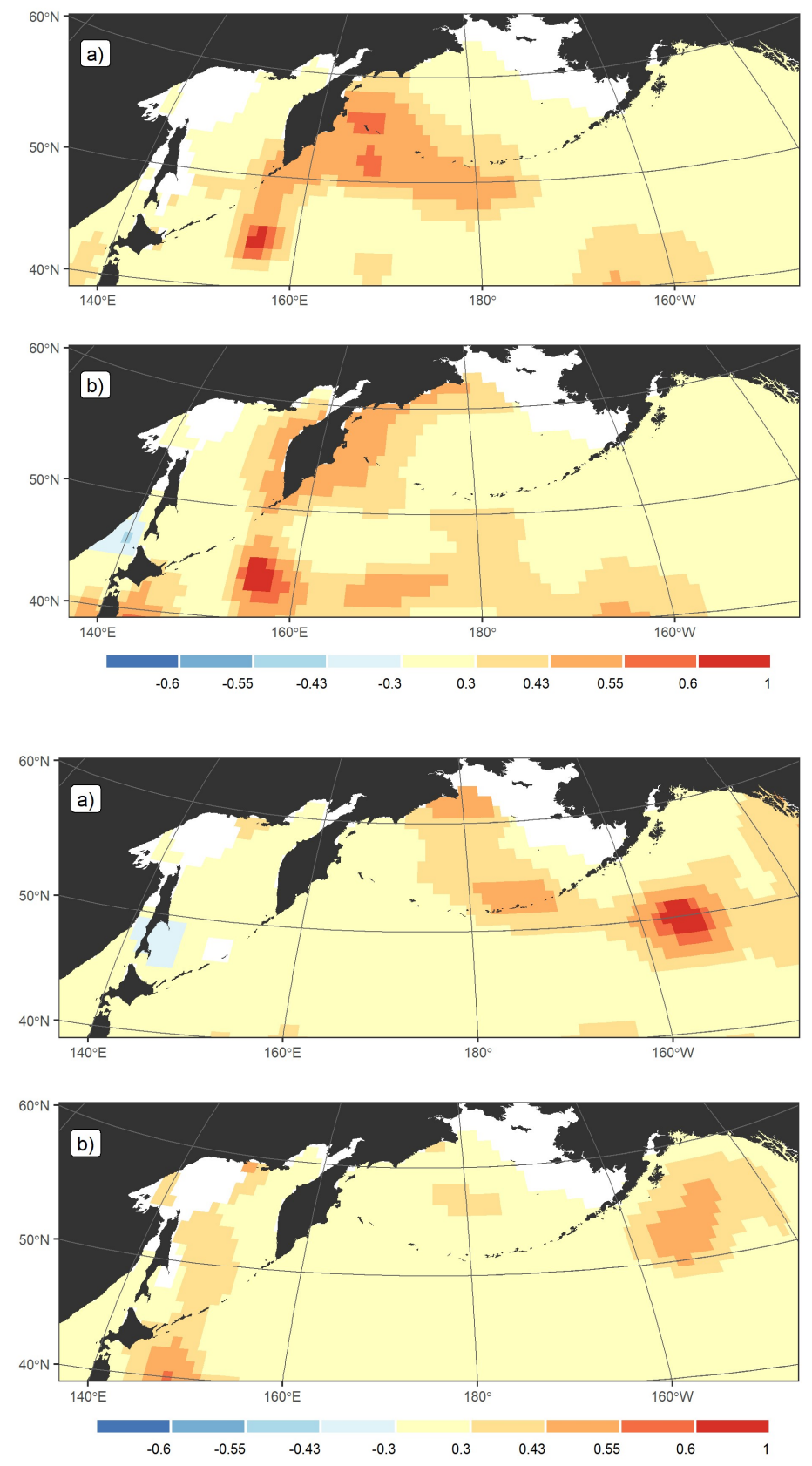

Fig. 5. Correlation patterns between catches of WK pink salmon in even years and heat content in the upper 0-100 m water layer for February (a) and April (b) during 1978-2020.
Fig. 6. Correlation patterns between catches of WK pink salmon in odd years and heat content in the upper 0-100 m water layer for December (a) and March (b) during 1979-2019.

The correlation relationship between the catches of the West Kamchatka (WK) pink salmon in even (dominant) years and heat content in the upper $100 \mathrm{~m}$ layer is less clear (Fig. 5). It can be supposed that their wintering area is located within the western Subarctic Gyre, between $150^{\circ} \mathrm{E}$ and $165^{\circ} \mathrm{E}$. It should be noted also that there are not any significant correlations between both the even-year catches of WK pink salmon and odd-year catches of EK pink salmon with the above-noted characteristics of ice cover in the Bering Sea.

The correlation coefficients between the heat content and catches of WK pink salmon in odd (non-dominant) years were lower than for all other stocks discussed above (Fig. 6). Perhaps, this is associated with minor changes in catch volumes from 1979-2017. The only exception was 2019, when the catch amounted to 60,200 metric tonnes. From the analysis of Figure 6, it can be supposed that pink salmon of this stock winter in the eastern Subarctic Gyre. This is partly confirmed by the relatively low, but statistically significant, correlation coefficients between the oddyear catches of WK pink salmon and latitude of the ice cover centroid in February and March, which, equal to 0.49 and $0.52(p<0.05)$, respectively. In this case, the expansion of ice cover can be considered as an indicator of the 
thermal state of waters in the Northeast Pacific and southern Bering Sea. The highest catch of WK pink salmon in odd years was obtained in 2019, when, as in 2018, the ice cover area in the Bering Sea was minimal.

Thus, the results of the analysis revealed a positive relationship between the thermal conditions of water during the wintering of all Kamchatka pink salmon stocks and their catches. However, their wintering areas differ. From 1978-2020, dominant odd-year generations of EK pink salmon and even-year generations of WK pink salmon were probably located within the western Subarctic Gyre, while odd-year generations of WK pink salmon were located in the eastern Subarctic Gyre, and even-year generations of EK pink salmon were mainly located in the southern Bering Sea.

\section{Conclusion}

1. The high heat content of surface waters in the North Pacific and Far Eastern seas in 2014-2019 contributed to the formation of favorable environmental conditions for salmon, and especially pink salmon spawning in the Kamchatka rivers, during the marine period of their life cycle.

2. The growth of catches of Far East pink salmon in 2014-2018 was largely associated with an unusual, rather sharp, increase in the catch of even generations of EK pink salmon which are not dominant for this stock. In 2018, its share in the total catch of Russian pink salmon reached almost $22 \%$.

3. Based on the analysis of the correlation between catches and heat content in the upper $100 \mathrm{~m}$ layer of the North Pacific region in the winter months, it can be assumed that for the dominant odd-year generations of EK pink salmon from 1978-2020 and for WK pink salmon of even years, wintering areas are located within the western Subarctic Gyre; for odd-year generations of WK pink salmon in the eastern part of the gyre; and for even-year generations of EK pink salmon, mainly, in the southern Bering Sea.

4. The main factors resulting in growth of catches of the even-year generations of EK pink salmon from 20142018 was the high heat content of surface waters in the northern North Pacific and an anomalous decrease in ice cover area in the Bering Sea combined with the displacement of its southern margin far to the north. These factors led to a widening area of favorable conditions for wintering in the southern Bering Sea.

5. The return of climatic conditions in the Bering Sea to the "normal" state in winter 2019-2020 resulted in worse survival of EK pink salmon born in 2018 and recovery of "saw-tooth" changes in abundance characteristics of this stock observed during the last decades, with high catches in odd years and low catches in even years.

\section{REFERENCES}

Eisner, L. 2020. Bering Sea: current status and trends. PICES Press 28(2): 29-32.

Good, S.A., M.J. Martin, and N.A. Rayner. 2013. EN4: Quality controlled ocean temperature and salinity profiles and monthly objective analyses with uncertainty estimates. J. Geophys. Res. Oceans 118(12): 6704-6716. doi.org/10.1002/2013JC009067.

Meier, W.N., F. Fetterer, M. Savoie, S. Mallory, R. Duerr, and J. Stroeve. 2017. NOAA/NSIDC Climate Data Record of Passive Microwave Sea Ice Concentration, Version 3. NSIDC: National Snow and Ice Data Center, Boulder. doi.org/10.7265/N59P2ZTG. 